\title{
Treatment of Diffuse
}

Cutaneous Systemic Sclerosis with Biologics, Small Molecules and Stem Cell Transplantation: What Is
the Evidence to Date?

\author{
Brigit Kersten, $M D^{1,2, *}$ \\ Madelon Vonk, MD, $P h D^{1}$
}

\author{
Address \\ ${ }^{1}$ Department of Rheumatology, Radboud University Nijmegen Medical Centre, \\ Nijmegen, The Netherlands \\ ${ }^{*}, 2$ Department of Rheumatology, Radboud University Medical centre, Geert \\ Grooteplein Zuid 10, 6525, GANijmegen, The Netherlands \\ Email: B.Kersten@radboudumc.nl
}

Published online: 26 February 2019

(C) The Author(s) 2019

This article is part of the Topical Collection on Scleroderma

Keywords Systemic sclerosis - Therapy · Biologics - Tyrosine kinase inhibitors - Autologous stemcell transplantation

\section{Abstract}

Purpose of review To give an overview of the current evidence for new therapies in diffuse cutaneous systemic sclerosis. Treatment with biologics, small molecules, and hemopoietic stem cell transplantation is reviewed.

Recent findings It is encouraging to see the amount of therapeutic studies in systemic sclerosis increasing. Although the effect of some therapeutic options is disappointing, in the near future, new trials will be published and several studies are underway.

Summary Systemic sclerosis is a serious life-threatening disease for which there is no cure available to date. Considering all forms of new therapies, autologous hematopoietic stem cell transplantation is the most effective therapy for well-selected patients with diffuse subtype despite the highest treatment related mortality. The effect of biologics in systemic sclerosis is disappointing, although data of several big trials are expected soon and could change this view. Tyrosine kinase inhibitors have not shown positive effects in the past and were hampered by side effects. The results of the thyrosine kinase inhibitor nitedanib in interstitial lung disease associated to systemic sclerosis are expected soon. Future research should focus on outcome measurements, combination therapy and treatment strategies in early disease. 


\section{Introduction}

Diffuse cutaneous systemic sclerosis (DcSSc) is an autoimmune disease characterized by inflammation, vasculopathy, and fibrosis. The most characterizing feature of systemic sclerosis (SSc) is skin thickening. If the skin thickening is present proximal from the elbows and knees or is apparent on the abdomen or chest, a patient can be classified as having diffuse cutaneous systemic sclerosis (DcSSc) [1]. Inflammation and subsequently fibrosis of internal organs is another important characteristic of the disease. Organs most frequently involved are the lungs, the heart, the gastrointestinal tract, and the kidneys. Organ involvement results in decreased organ function and is associated with a poor prognosis. Although life expectancy has increased especially in patients with the diffuse subtype, over $50 \%$ of the patients die as a result of SSc. The main causes of death are interstitial lung disease (ILD), pulmonary hypertension, and heart disease [2].

Although several treatment options are available, there is no curing treatment to date. Present therapies postpone disease deterioration but do not prevent serious disease complications. Therapeutic options for DcSSc according to the EULAR treatment recommendations 2016 are methotrexate, cyclophosphamide, or mycophenolate mofetil and in selected patients autologous stem cell transplantation [3]. Methotrexate is efficient for stabilizing or reducing skin involvement as well as improving quality of life but evidence of efficacy in organ involvement is lacking [4]. Patients with lung involvement or progressive skin thickening are treated with either cyclophosphamide, or mycophenolaat mofetil.
In the absence of a cure, the intended treatment goal for patients with DcSSc is prevention of progression of the disease. The effect of therapy is determined by several outcome measurements. The most used outcomes are the modified Rodnan skin score (mRSS) to determine the extent of skin involvement, pulmonary function tests, namely forced vital capacity (FVC) and diffusion capacity (DLCO) and high-resolution CT-scan (HRCT) of the lungs to define the extent of pulmonary involvement. Furthermore, patient-reported outcomes on quality of life are regarded as important outcome measurements. Because all separate outcome measures have flaws, a combination of several of these is used in newer trials, for example, the CRISS, which combines mRSS, FVC, HAQ-DI, patient global assessment, and physician global assessment [5].

In other rheumatic diseases, biologics have proven high value. Taking the role of $\mathrm{B}$ - and T-cells and the inflammatory cytokines involved in the pathogenesis of systemic sclerosis into account, it seems rational to examine the efficacy and safety of biologics for this indication. A considerable amount of trails on different biologics have been reported. In this review, we give an overview of the current evidence of their efficacy and safety in systemic sclerosis.

Furthermore, we will discuss new anti-fibrotic treatments currently approved for the treatment of idiopathic pulmonary fibrosis which are evaluated in SSc in ongoing trails. To conclude, we give an overview of the evidence for the efficacy and safety of autologous stem cell transplantation in patients with DcSSc.

\section{Treatment}

Infliximab is a chimeric IgG1 monoclonal antibody that binds both soluble and receptor bound TNF- $\alpha$. TNF- $\alpha$ is involved in the pathogenesis of systemic sclerosis and is found in inflammatory cutaneous infiltrates. It is controversial whether anti-TNF- $\alpha$ therapy is anti- or profibrotic. In vitro studies show that TNF- $\alpha$ inhibitors are antifibrotic, in vivo animal studies show the contrary [6]. An explanation for the ambiguous results could be that the effect of therapy relates to the inflammatory state of the patient. Patients in a more inflammatory state are more prone to respond positively to TNF- $\alpha$ blockage $[7,8]$. A few studies have been performed using TNF- $\alpha$ blockage as treatment option for DcSSc. 
A small open-label trial has been performed on the treatment of 16 DcSSc patients with infliximab. In this trial, infliximab was given in a dose of $5 \mathrm{mg} / \mathrm{kg}$ every 8 weeks until week 22 after loading doses at week 0, 2, and 6 [9]. At week 26 , the mRSS was not significantly changed compared to baseline, but the level of type III collagen was significantly reduced as was the secretion of collagen type I by dermal fibroblasts compared to baseline. Also in SSc, the main safety issue of this treatment was infusion reactions associated with antibody development. Results of this study were hampered by the low number of patients, the lack of a control group, and therefore the absence of randomization [9]. A second small observational study on infliximab was performed. This study showed no significant effect on skin involvement after 6 months of follow-up as well [10].

Etanercept, a human TNF-receptor p75 Fc fusion protein that bounds TNF, was used in a small observational study. Eighteen systemic sclerosis patients were treated with etanercept for a duration ranging from 2 to 22 months, resulting in no significantly improvement of the mRSS [11, 12]. Taking the results of the studies with TNF- $\alpha$ blockage in SSc together, the results are disappointing.

When therapy with TNF blockage is considered, latent tuberculosis infection and chronic hepatitis B infection should be ruled out before starting, because of the risk of a flare. Congestive heart failure is the most important contraindication for therapy. Vaccinations with living organisms should not be administered to patients during therapy. Combination of different biologics is discouraged.

Abatacept is a human fusion protein that blocks the co-stimulatory CD80CD86 molecule. This blockage prevents the stimulation of the antigen presenting cells on specific $\mathrm{T}$ cells, which prevents these $\mathrm{T}$ cells from producing different cytokines. Activated T cells and their cytokines are involved in the pathogenesis of systemic sclerosis as has been demonstrated by several observation fundamental studies [6].

In a small randomized controlled trial, 7 DcSSc patients were randomized to abatacept and 3 to placebo. Abatacept was dosed according to bodyweight, $500 \mathrm{mg} /$ dose for patients $<60 \mathrm{~kg}, 750 \mathrm{mg} /$ dose for patients between 60 and $100 \mathrm{~kg}$ and $1000 \mathrm{mg} /$ dose for those over $100 \mathrm{~kg}$. Infusions were repeated every 28 days, which is the standard dosage interval in rheumatoid arthritis. The primary endpoint of the study was the improvement of mRSS after 24 weeks. The mRSS differed significantly between the intervention and the placebo group [13].

In the near future, the results of a new randomized controlled trial with abatacept will become available, providing evidence on the efficacy of this treatment option in SSc (clinicaltrials.gov).

The most common side effect of abatacept is upper airway infection. Before starting, abatacept chronic infections should be ruled out. 
CD20-antigen on B cells and by binding to the Fc region leads to cell death. As B cells seem to have a pathogenic role in systemic sclerosis, preclinical studies have provided the rationale of possible effectiveness of rituximab for this disease.

To date, one randomized controlled trial and several open label observational trials are reported besides case series. The randomized controlled trial consisted of 14 patients with a disease duration ranging from 1 to 15 years. Patients received 2 infusions of $1000 \mathrm{mg}$ rituximab at baseline and month 6 and were compared to patients in the control group who received standard treatment consisting of either prednisone, cyclophophamide, or mycophenolate mofetil. At month 12, a significant increase in FVC and DLCO and decrease of mRSS were found in the rituximab patients. This study was extended containing only the patients with interstitial lung disease (ILD) at baseline. After prolonged treatment with rituximab infusion at month 12 and 18, the improvement of both lung and skin sustained significantly during 2 years follow-up. The same group has conducted a multicenter open-label comparative trial on treatment of DcSSc patients with ILD and a mean disease duration of 2.55.7 years. Thirty-three patients were treated with rituximab (each cycle consisting of 4 weekly infusions of cycles of $375 \mathrm{mg} / \mathrm{m}^{2}$ ) every 6 months in different schemes ranging from 5 to 7 years. Eighteen patients received standard treatment consisting of azathioprine, methotrexate, or mycophenolate mofetil. Although no statistical difference in FVC and DLCO was found after 2 years of follow-up, a statistical significant difference in FVC was found after 7 years, but the number of patients remaining in each group was low. The mRSS was reported significantly lower in de rituximab group at 1,2, and 3 years of follow-up [14-16]. Another open-label trial of eight patients with early DcSSc and arthritis, mean disease duration of 10 months, found a statistical significant improvement in mRSS and in disease activity score (DAS) at month 24 with stabilization of internal organ involvement [17]. Prevention of development of internal organ involvement was confirmed in two other open label trials; the first with 20 patients with mean disease duration of 30.4 months showing a statistical significant increase of FVC at month 12. In this study, patients without ILD at baseline did not develop ILD during follow-up and mRSS improved in all but one patient with more than $10 \%$ at month 12 . Furthermore, patients reported outcomes improved significantly [18]. In a second prospective, observational study on 15 early DcSSc patients mRSS did not change significantly after 6 and 12 months but none of patients showed progressive major organ involvement [19].

In a nested case control study in 63 DcSSc patients with a disease duration ranging from 3 to 11 years treated with rituximab, compared to matched controls treated with conventional treatment including mycophenolate mofetil, cyclophosphamide, and methotrexate, revealed a significant improvement of mRSS after 6 months. Pulmonary function was tested in patients with ILD at baseline. After 6 months, the FVC was stable and the DLCO improved significantly [20]. The different case series with rituximab in early DcSSc report the same results, possible improvement of skin involvement and stabilization of ILD [21-23]. 
Furthermore, data analysis of a single-center randomized double blind placebo-controlled trial will become available in the near future. Data from the RECITAL trial, a multicenter, prospective, randomized, double-blind, double-placebo controlled trial on rituximab compared to cyclophosphamide will become apparent. In this trial, patients with ILD associated to connective tissue disease (systemic sclerosis, idiopathic inflammatory myositis, and mixed connective tissue disease) will be treated with rituximab $1 \mathrm{~g}$ twice in 2 weeks compared to cyclophosphamide $600 \mathrm{mg} / \mathrm{m}^{2}$ pulse therapy per month for 6 months. Primary endpoint is change in forced vital capacity (FVC) at week 24 . (clinicaltrial.gov).

Taking into account that to date only one randomized controlled trial and several small open label studies have been published with rituximab, efficacy on skin involvement is disputable; however, rituximab could have a positive effect on ILD and could have a role in prevention of ILD.

Before administering rituximab, chronic hepatitis B infection must be excluded. The most common side effects are infusion reactions.

Tocilizumab is a recombinant humanized monoclonal antibody against the IL6 receptor. IL- 6 is involved in systemic sclerosis pathogenesis and has shown a direct fibrotic effect [6]. The biologic tocilizumab has been evaluated for its efficacy in systemic sclerosis in the recent years. Studies with tocilizumab in systemic sclerosis are performed with tocilizumab administered subcutaneously in a dose of $162 \mathrm{mg} /$ week. Two randomized controlled trials are completed; the results of one of them will become available in the near future (clinicaltrials.gov). Several small case reports have already been described [24, 25]. These case reports describe improvement of skin thickening after 6 months in 2 patients and improvement of range of motion in one other patient 16 months after therapy [24, 25].

The FaSScinate trial is a phase 2 double blind randomized controlled trial on tocilizumab compared to placebo in DcSSc patients with a disease duration shorter than 5 years, without signs of ILD. In this trial 78 patients were enrolled of which 43 were treated with tocilizumab and 44 with placebo for 48 weeks. The mRSS did not significantly differ between both treatment groups at week 24. A small, not significant decline in FVC was reported $[26 \bullet \bullet]$.

In the EUSTAR network, an observational study to evaluate the efficacy and safety of tocilizumab and abatacept in SSc-associated arthritis and SScassociated myositis was performed. Twenty patients with SSc arthritis and 7 patients with SSc-myositis, all refractory to DMARDS and cyclophosphamide were included. Fifteen patients received tocilizumab $8 \mathrm{mg} / \mathrm{kg} /$ month and 12 abatacept $10 \mathrm{mg} / \mathrm{kg} / \mathrm{month}$ all patients with SSc myopathy received abatacept. After 5 months of tocilizumab, DAS- 28 and it components improved significantly and 10/15 patients achieved an EULAR good response. After 11 months treatment with abatacept, joint parameters improved significantly; however, abatacept did not improve muscle outcome measures in SSc myopathy. No significant improvement for skin involvement or ILD was seen in both groups [27]. The results of the phase 
III study with tocilizumab in SSc, the FocuSSced trial, provide more information about the efficacy and have been presented in abstract form, showing trend of benefit in skin but significant prevention of lung deterioration (acrabstracts.org/abstract/efficacy-and-safety-of-tocilizumab-forthe-treatment-of-systemic-sclerosis-results-from-a-phase-3-randomizedcontrolled-trial).

Tocilizumab must not be administered before active infection or latent tuberculosis infection is ruled out. When neutrophils are $<2.0 \times 10^{9} / \mathrm{L}$ tocilizumab is contraindicated. Tocilizumab indirectly blocks the formation of Creactive protein, this inflammatory parameter is therefore invaluable. Most common side effects of therapy are upper airway infections and hypercholesterolemia.

In the recent years, the use of tyrosine kinase inhibitors as potential treatment for SSc has become of interest. In the near future, the data of the first clinical randomized controlled trial on nintedanib in SSc-associated ILD, the SCENSCIS trial, will become available [28•]. Nintedanib is a tyrosine kinase inhibitor registered for the treatment of idiopathic pulmonary fibrosis (IPF). It blocks VEGF, PDGF, and TGF $\beta$-induced proliferation and migration of fibroblasts and furthermore decreases extracellular matrix protein synthesis and as such could influence SSc pathogenesis [29]. In the SCENSCIS trial, 580 patients with SSc-ILD were randomized between nintedanib and placebo. The primary endpoint is the annual rate of decline in FVC assessed over 52 weeks and the effect on skin involvement is among secondary outcomes (clinicaltrials.gov).

Before starting nintedanib liver chemistry must be evaluated. Treatment should be stopped instantly when signs of hepatitis develop. The therapy is contraindicated in patients with peanut or soya allergy. Most often reported side effects are nausea, abdominal discomfort, and diarrhea.

Imatinib, another tyrosine kinase inhibitor, has been used in a few studies on patients with SSc-ILD. Imatinib interferes with the tyrosine kinase receptors downstream of the receptors for transforming growth factor beta (TGF- $\beta$ ) and pallet-derived growth factor (PEGF), which are thought to be key signaling molecules in the formation of SSc-associated fibrosis. The randomized placebo controlled trial to investigate the effectiveness of imatinib in active DcSSc was terminated because of side effects [30]. Several open label studies with imatinib were reported. In a study of 17 patients with DcSSc treated for 24 months with imatinib the mRSS significantly reduced [31].

In an observational study in patients with SSc-ILD unresponsive to cyclophosphamide therapy, 30 patients were enrolled and treated with imatinib. Stabilization of pulmonary involvement was found in the majority of the patients after 6 months of low-dose treatment. There was no significant change in skin involvement [32].

When considering treating patients with imatinib, patients should be evaluated for chronic hepatitis B infection and congestive heart failure. During treatment full blood count, liver chemistry and kidney function should be monitored. Physical examination should focus on signs of heart failure. Side effects are frequent, and are most often gastrointestinal related but, headache and muscle and joint pain are also common. 
To date, the evidence for the use of anti-fibrotic therapy in SSc is small and ambivalent. Data on the SENSCIS trial will hopefully provide the evidence for its use in systemic sclerosis.

\section{Hematopoietic stem cell transplantation}

In the past decade, data on three major randomized clinical trials on the treatment of severe diffuse cutaneous systemic sclerosis with autologous hematopoietic stem cell transplantation (HSCT) have become available. Table 1 reports the study characteristics in more detail. The positive effect of HSCT in systemic sclerosis on survival, mRSS, pulmonary involvement, and quality of

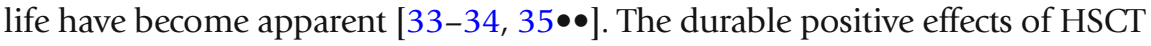
with a considerable decrease in mortality due to disease progression were reported after longer follow-up [36].

Hematopoietic stem cell transplantation is conducted in two phases. First, hematopoietic progenitors are mobilized and harvested by leukapheresis and enriched for CD34+. The second phase consists of conditioning aiming to achieve intense lymphocyte ablation followed by reinfusion of peripheral

\begin{tabular}{|c|c|c|c|}
\hline & ASSIST[33] & ASTIS[34] & SCOT[35••] \\
\hline $\begin{array}{l}\text { Study } \\
\text { design }\end{array}$ & $\begin{array}{l}\text { Open-label, single } \\
\text { center, } \\
\text { randomized } \\
\text { controlled }\end{array}$ & $\begin{array}{l}\text { Open-label, multicenter, } \\
\text { controlled phase } 3 \text { trial }\end{array}$ & $\begin{array}{l}\text { Open-label, } \\
\text { multicenter, } \\
\text { controlled phase } 3 \\
\text { trial }\end{array}$ \\
\hline $\begin{array}{l}\text { Inclusion } \\
\text { period }\end{array}$ & 2006-2009 & 2001-2009 & 2005-2011 \\
\hline $\begin{array}{r}\text { Number of } \\
\text { patients } \\
\text { included }\end{array}$ & 19 & 156 & 75 \\
\hline \multirow[t]{2}{*}{ Control } & & $\begin{array}{l}\text { Cyclophosphamide } \\
\text { (6 i.v. pulses) }\end{array}$ & $\begin{array}{l}\text { Cyclophosphamide (12 } \\
\text { i.v. pulses) }\end{array}$ \\
\hline & $\begin{array}{l}\text { Cyclophosphamide } \\
\text { (11 i.v. pulses) }\end{array}$ & & \\
\hline Primary & endpoint & $\begin{array}{l}\text { Improvement at } 12 \text { months, } \\
\text { defined as a decrease in } \\
\text { mRSS or increase in FVC. }\end{array}$ & $\begin{array}{l}\text { Event-free survival, } \\
\text { defined as time from } \\
\text { randomization until } \\
\text { the occurrence of } \\
\text { death (by any cause) } \\
\text { of development of } \\
\text { major organ } \\
\text { involvement (heart, } \\
\text { lung or kidney) }\end{array}$ \\
\hline $\begin{array}{l}\text { Change in } \\
\text { global } \\
\text { rank } \\
\text { composite } \\
\text { scores at }\end{array}$ & 54 months & & \\
\hline
\end{tabular}


blood autologous CD34+ stem cells. Both phases can be applied in a different manner. In the ASSIST and ASTIS trial, the peripheral stem cell mobilization was performed using cyclophosphamide $\left(2-4 \mathrm{~g} / \mathrm{m}^{2}\right)$ and granulocyte colonystimulating factor $(10 \mu \mathrm{g} / \mathrm{kg} / \mathrm{day})$. In the SCOT trial, only granulocyte colonystimulating factor was used. After aphaeresis, the CD34+ cells were selected in all but the ASSIST trial, were no selection of cells took place. At least 2 weeks after the leukapheresis the conditioning is performed. The conditioning regime in the ASTIS and the ASSIST trial consisted of cyclophosphamide intravenous therapy ( $200 \mathrm{mg} / \mathrm{kg}$ in 4 consecutive days) followed by intravenous rabbit antithymocyte globulin (6-7.5 mg/kg in total divided in 3-4 days) administered with $1000 \mathrm{mg}$ methylprednisolone. After the conditioning regime, the stem cells were re-infused $[33,34]$. In the SCOT trial, the conditioning was performed using fractionated total body irradiation (800cGY), cyclophopsphamide $(120 \mathrm{mg} / \mathrm{kg})$ and equine anti-thymocyte globulin $(90 \mathrm{mg} / \mathrm{kg})$. Pulmonary and renal shields were applied to limit organ exposure. After the conditioning regime, CD34+ stem cells were administered again.

In order to be eligible for HSCT, the three trials used different criteria, but all patients had DcSSc with significant skin thickening, a relatively short disease duration and low tot modest organ involvement. Significant organ involvement (pulmonary, cardial, or kidney) was an absolute contra-indication for HSCT.

In the single-center randomized phase 2 trial, the ASISST Study, 10 patients were treated by HSCT. All improved in mRSS and pulmonary function already within the first year after treatment compared to none of the 9 patients treated with cyclophosphamide. The European ASTIS study consisted of 156 patients; 79 received HSCT and were compared to 77 patients treated with 12 monthly pulses of cyclophosphamide $750 \mathrm{mg} / \mathrm{kg}$. After 5 years of follow-up, event-free survival was almost $80 \%$ in the HSCT group and $65 \%$ in the cyclophosphamide group, despite $10 \%$ treatment-related mortality. Results of secondary end points such as mRSS, pulmonary function, and HAQ were in favor of HSCT. In the SCOT trial patients were randomized between HSCT (36 patients) and i.v. cyclophoshamide (39 patients). The event-free survival after 54 months in the HSCT group was $79 \%$ compared to $50 \%$ in the cyclophosphamide group. Treatment related mortality was $3 \%$ after 54 months [35••].

Although HSCT seems to be the most powerful disease modifying therapy for well-selected patients with early DcSSc, this treatment is hampered by the highest treatment-related mortality of all therapies given in DcSSc. Patients selection, regime of mobilization, and conditioning as well as local experience of the transplantation center seem to play important roles. Strict criteria for the use and timing of HSCT in clinical practice are lacking. In clinical practice, patients with DcSSc at risk for deterioration and early disease are selected for this treatment option. Future studies should focus on identifying factors for the most eligible patients, reducing treatment-related mortality, optimizing mobilization and condition regimes, and choosing the optimal timing of this therapy (Table 1).

\section{Conclusion}

Systemic sclerosis is a serious life-threatening disease for which there is no cure to date. Considering all forms of new therapies, autologous hematopoietic stem cell transplantation is the most effective therapy for well-selected patients 
despite the highest treatment-related mortality. Until now, the effect of biologics in systemic sclerosis is disappointing, although data of a several big trials are expected soon and could change this vision. The use of tyrosine kinase inhibitors was hampered with side effects and lack of efficacy, but the results of nintedanib in SSc-ILD could change the scene for treatment options in systemic sclerosis, especially for patients with ILD. It is important to consider other (composite) outcome measurement for future research, which perhaps measure effectiveness of therapy more adequately. Much is happening in the field of systemic sclerosis which is comforting. Besides research aiming to define better outcome measures, focus of future research should be the effectiveness and safety of combination therapy and treatment of early disease that is currently not treated. By treating systemic sclerosis early deadly and disabling complications may possibly be prevented.

\section{Compliance with Ethical Standards}

All reported studies/experiments with human or animal subjects performed by the authors have been previously published and complied with all applicable ethical standards (including the Helsinki declaration and its amendments, institutional/national research committee standards, and international/national/institutional guidelines).

\section{Conflict of Interest}

Dr. Vonk reports grants and non-financial support from Actelion, grants from Therabel, from Boeringer Ingelheim, from GSK, from Roche, outside the submitted work. Dr. Kersten has nothing to disclose.

Open Access This article is distributed under the terms of the Creative Commons Attribution 4.0 International License (http://creativecommons.org/licenses/by/4.0/), which permits unrestricted use, distribution, and reproduction in any medium, provided you give appropriate credit to the original author(s) and the source, provide a link to the Creative Commons license, and indicate if changes were made.

\section{Publisher's Note}

Springer Nature remains neutral with regard to jurisdictional claims in published maps and institutional affiliations.

\section{References and Recommended Reading}

Papers of particular interest, published recently, have been highlighted as:

- Of importance

-. Of major importance

1. LeRoy EC, Black C, Fleischmajer R, Jablonska S, Krieg T, Medsger TA Jr, et al. Scleroderma (systemic sclerosis): classification, subsets and pathogenesis. J Rheumatol. 1988;15(2):202-5.

2. Tyndall AJ, Bannert B, Vonk M, Airo P, Cozzi F, Carreira $\mathrm{PE}$, et al. Causes and risk factors for death in systemic sclerosis: a study from the EULAR Scleroderma Trials and Research (EUSTAR) database. Ann Rheum Dis.

2010;69(10):1809-15. https://doi.org/10.1136/ard. 2009.114264.

3. Kowal-Bielecka O, Landewe R, Avouac J, Chwiesko S, Miniati I, Czirjak L, et al. EULAR recommendations for the treatment of systemic sclerosis: a report from the EULAR Scleroderma Trials and Research group (EUSTAR). Ann Rheum Dis. 2009;68(5):620-8. https://doi.org/10.1136/ard.2008.096677. 
4. van den Hoogen FH, Boerbooms AM, Swaak AJ, Rasker JJ, van Lier HJ, van de Putte LB. Comparison of methotrexate with placebo in the treatment of systemic sclerosis: a 24 week randomized double-blind trial, followed by a 24 week observational trial. Br J Rheumatol. 1996;35(4):36472.

5. Khanna D, Berrocal VJ, Giannini EH, Seibold JR, Merkel PA, Mayes MD, et al. The American College of Rheumatology provisional composite response index for clinical trials in early diffuse cutaneous systemic sclerosis. Arthritis Rheum (Hoboken, NJ). 2016;68(2):299-311. https://doi.org/10.1002/art. 39501.

6. Avouac J, Allanore Y. Targeted immunotherapies in systemic sclerosis. Clin Exp Rheumatol. 2014;32(2 Suppl 81):165-72.

7. Bruni C, Praino E, Allanore Y, Distler O, Gabrielli A, Iannone $\mathrm{F}$, et al. Use of biologics and other novel therapies for the treatment of systemic sclerosis. Expert Rev Clin Immunol. 2017;13(5):469-82. https://doi. org/10.1080/1744666x.2017.1263153.

8. Distler JH, Schett G, Gay S, Distler O. The controversial role of tumor necrosis factor alpha in fibrotic diseases. Arthritis Rheum. 2008;58(8):2228-35. https://doi.org/ 10.1002/art.23645.

9. Denton CP, Engelhart M, Tvede N, Wilson H, Khan K, Shiwen $\mathrm{X}$, et al. An open-label pilot study of infliximab therapy in diffuse cutaneous systemic sclerosis. Ann Rheum Dis. 2009;68(9):1433-9. https://doi.org/10. 1136/ard.2008.096123.

10. Bosello S, De Santis M, Tolusso B, Zoli A, Ferraccioli G. Tumor necrosis factor-alpha inhibitor therapy in erosive polyarthritis secondary to systemic sclerosis. Ann Intern Med. 2005;143(12):918-20.

11. Lam GK, Hummers LK, Woods A, Wigley FM. Efficacy and safety of etanercept in the treatment of scleroderma-associated joint disease. J Rheumatol. 2007;34(7):1636-7.

12. Phumethum V, Jamal S, Johnson SR. Biologic therapy for systemic sclerosis: a systematic review. J Rheumatol. 2011;38(2):289-96. https://doi.org/10.3899/jrheum. 100361

13. Chakravarty EF, Martyanov V, Fiorentino D, Wood TA, Haddon DJ, Jarrell JA, et al. Gene expression changes reflect clinical response in a placebo-controlled randomized trial of abatacept in patients with diffuse cutaneous systemic sclerosis. Arthritis Res Ther. 2015;17:159. https://doi.org/10.1186/s13075-015-0669-3.

14. Daoussis D, Liossis SN, Tsamandas AC,

Kalogeropoulou C, Kazantzi A, Sirinian C, et al. Experience with rituximab in scleroderma: results from a 1year, proof-of-principle study. Rheumatology (Oxford, England). 2010;49(2):271-80. https://doi.org/10. 1093/rheumatology/kep093.

15. Daoussis D, Liossis SN, Tsamandas AC,

Kalogeropoulou C, Paliogianni F, Sirinian C, et al. Effect of long-term treatment with rituximab on pulmonary function and skin fibrosis in patients with diffuse systemic sclerosis. Clin Exp Rheumatol. 2012;30(2 Suppl 71):S17-22.

16. Daoussis D, Melissaropoulos K, Sakellaropoulos G, Antonopoulos I, Markatseli TE, Simopoulou T, et al. A multicenter, open-label, comparative study of B cell depletion therapy with rituximab for systemic sclerosis-associated interstitial lung disease. Semin Arthritis Rheum. 2017;46(5):625-31. https://doi.org/10. 1016/j.semarthrit.2016.10.003.

17. Smith V, Piette Y, van Praet JT, Decuman S, Deschepper E, Elewaut D, et al. Two-year results of an open pilot study of a 2-treatment course with rituximab in patients with early systemic sclerosis with diffuse skin involvement. J Rheumatol. 2013;40(1):52-7. https:// doi.org/10.3899/jrheum.120778.

18. Bosello SL, De Luca G, Rucco M, Berardi G, Falcione M, Danza FM, et al. Long-term efficacy of B cell depletion therapy on lung and skin involvement in diffuse systemic sclerosis. Semin Arthritis Rheum. 2015;44(4):428-36. https://doi.org/10.1016/j. semarthrit.2014.09.002.

19. Lafyatis R, Kissin E, York M, Farina G, Viger K, Fritzler $\mathrm{MJ}$, et al. B cell depletion with rituximab in patients with diffuse cutaneous systemic sclerosis. Arthritis Rheum. 2009;60(2):578-83. https://doi.org/10.1002/ art.24249.

20. Jordan S, Distler JH, Maurer B, Huscher D, van Laar JM, Allanore Y, et al. Effects and safety of rituximab in systemic sclerosis: an analysis from the European Scleroderma Trial and Research (EUSTAR) group. Ann Rheum Dis. 2015;74(6):1188-94. https://doi.org/10. 1136/annrheumdis-2013-204522.

21. Giuggioli D, Lumetti F, Colaci M, Fallahi P, Antonelli A, Ferri C. Rituximab in the treatment of patients with systemic sclerosis. Our experience and review of the literature. Autoimmun Rev. 2015;14(11):1072-8. https://doi.org/10.1016/j.autrev.2015.07.008.

22. Sari A, Guven D, Armagan B, Erden A, Kalyoncu U, Karadag $\mathrm{O}$, et al. Rituximab experience in patients with long-standing systemic sclerosis-associated interstitial lung disease: a series of 14 patients. J Clin Rheumatol. 2017;23(8):411-5. https://doi.org/10.1097/rhu. 0000000000000584.

23. Thiebaut M, Launay D, Riviere S, Mahevas T, Bellakhal $S$, Hachulla E, et al. Efficacy and safety of rituximab in systemic sclerosis: French retrospective study and literature review. Autoimmun Rev. 2018;17(6):582-7. https://doi.org/10.1016/j.autrev.2017.12.010.

24. Shima Y, Hosen N, Hirano T, Arimitsu J, Nishida S, Hagihara $\mathrm{K}$, et al. Expansion of range of joint motion following treatment of systemic sclerosis with tocilizumab. Mod Rheumatol. 2015;25(1):134-7. https:// doi.org/10.3109/14397595.2013.874749.

25. Shima Y, Kuwahara Y, Murota H, Kitaba S, Kawai M, Hirano T, et al. The skin of patients with systemic sclerosis softened during the treatment with anti-IL-6 receptor antibody tocilizumab. Rheumatology (Oxford, England). 2010;49(12):2408-12. https://doi.org/ 10.1093/rheumatology/keq275. 
26.• Khanna D, Denton CP, Jahreis A, van Laar JM, Frech TM, Anderson ME, et al. Safety and efficacy of subcutaneous tocilizumab in adults with systemic sclerosis (faSScinate): a phase 2, randomised, controlled trial. Lancet (London, England). 2016;387(10038):263040. https://doi.org/10.1016/s0140-6736(16)00232-4

This is a large randomized controlled trial with important conclusions concerning the use of tocilizumab in systemic sclerosis.

27. Elhai M, Meunier M, Matucci-Cerinic M, Maurer B, Riemekasten G, Leturcq T, et al. Outcomes of patients with systemic sclerosis-associated polyarthritis and myopathy treated with tocilizumab or abatacept: a EUSTAR observational study. Ann Rheum Dis. 2013;72(7):1217-20. https://doi.org/10.1136/ annrheumdis-2012-202657.

28. Distler O, Brown KK, Distler JHW, Assassi S, Maher TM, Cottin V et al. Design of a randomised, placebocontrolled clinical trial of nintedanib in patients with systemic sclerosis-associated interstitial lung disease (SENSCIS). Clin Exp Rheumatol. 2017;35 Suppl 106(4):75-81.

In the near future, data on this trial will become available; these data could have major implications for the current therapy of SSc-ILD.

29. Richeldi L, du Bois RM, Raghu G, Azuma A, Brown KK, Costabel U, et al. Efficacy and safety of nintedanib in idiopathic pulmonary fibrosis. N Engl J Med. 2014;370(22):2071-82. https://doi.org/10.1056/ NEJMoa1402584.

30. Pope J, McBain D, Petrlich L, Watson S, Vanderhoek L, de Leon F, et al. Imatinib in active diffuse cutaneous systemic sclerosis: results of a six-month, randomized, doubleblind, placebo-controlled, proof-of-concept pilot study at a single center. Arthritis Rheum. 2011;63(11):3547-51. https://doi.org/10.1002/art.30549.

31. Gordon J, Udeh U, Doobay K, Magro C, Wildman H, Davids $\mathrm{M}$, et al. Imatinib mesylate (Gleevec) in the treatment of diffuse cutaneous systemic sclerosis: results of a 24-month open label, extension phase, single-centre trial. Clin Exp Rheumatol. 2014;32(6 Suppl 86):S-189-93.

32. Fraticelli P, Gabrielli B, Pomponio G, Valentini G, Bosello S, Riboldi P, et al. Low-dose oral imatinib in the treatment of systemic sclerosis interstitial lung disease unresponsive to cyclophosphamide: a phase II pilot study. Arthritis Res Ther. 2014;16(4):R144. https://doi.org/10.1186/ar4606.

33. Burt RK, Shah SJ, Dill K, Grant T, Gheorghiade M, Schroeder J, et al. Autologous non-myeloablative haemopoietic stem-cell transplantation compared with pulse cyclophosphamide once per month for systemic sclerosis (ASSIST): an open-label, randomised phase 2 trial. Lancet (London, England).

2011;378(9790):498-506. https://doi.org/10.1016/ s0140-6736(11)60982-3.

34. van Laar JM, Farge D, Sont JK, Naraghi K, Marjanovic Z, Larghero J, et al. Autologous hematopoietic stem cell transplantation vs intravenous pulse cyclophosphamide in diffuse cutaneous systemic sclerosis: a randomized clinical trial. JAMA. 2014;311(24):2490-8. https://doi.org/10.1001/jama.2014.6368.

35.• Sullivan KM, Goldmuntz EA, Keyes-Elstein L, McSweeney PA, Pinckney A, Welch B, et al. Myeloablative autologous stem-cell transplantation for severe scleroderma. N Engl J Med. 2018;378(1):35-47

This study contributes to the evidence of the effectiveness and safety of autologous stem-cell transplantation.

36. Vonk MC, Marjanovic Z, van den Hoogen FH, Zohar S, Schattenberg AV, Fibbe WE, et al. Long-term follow-up results after autologous haematopoietic stem cell transplantation for severe systemic sclerosis. Ann Rheum Dis. 2008;67(1):98-104. https://doi.org/10. 1136/ard.2007.071464. 